\title{
Analisa Model Rapid Application Development Dalam Membangun Sistem Informasi Sekolah Mengemudi
}

\author{
Vivi Rahmawati ${ }^{1}$, Susy Rosyida ${ }^{2}$ \\ ${ }^{1}$ Universitas Bina Sarana Informatika \\ e-mail: vivirahmawati2302@gmail.com \\ ${ }^{2}$ Sekolah Tinggi Manajemen Informatika dan Komputer Nusa Mandiri \\ e-mail: susyrosyida@gmail.com
}

\begin{abstract}
Technological developments, especially in the automotive sector, make automotive companies competing to produce vehicles or means of transportation that are in accordance with the demands of society at this time. The public wants a means of transportation that is safe, comfortable, environmentally friendly and economical. To drive a private vehicle properly and correctly one of them follows training from institutions or driving schools. In this study, the authors helped overcome it by Building a Driving School Information System by analyzing using the Rapid Application Development (RAD) model. Use the Rapid Application Development (RAD) model for software development by minimizing the planning stage and maximizing prototype development. Through this system, prospective drivers can find out all information relating to driving schools, such as training schedules, names of instructors, costs required, types of cars available and comments of prospective drivers who have attended training at the school. This information system is very important for prospective drivers, it is also very useful for the driving school to display all information related to driving learning that will be applied.
\end{abstract}

Keywords: Information Systems, Driving Schools, Rapid Application Development

\section{PENDAHULUAN}

Kemajuan bidang transportasi pada saat ini seiring dengan kemajuan bidang teknologi otomotif sudah mampu menghasilkan alat-alat transportasi yang modern (Lesmono, 2019), nyaman dan ramah lingkungan baik yang bersifat massal maupun individual untuk mempermudah masyarakat dalam perjalanannya (Riyanto, Rosyida, \& Ridwansyah, 2018). Untuk transportasi massal di kota-kota besar tersedia kereta api listrik dan juga bus dalam kota yang menggunakan bahan bakar gas sehingga menghasilkan emisi gas buang yang aman untuk lingkungan (Jaya \& Hasddin, 2019). Sedangkan untuk kendaraan yang bersifat pribadi juga banyak diproduksi mobil-mobil dengan teknologi yang ramah lingkungan dan dapat mendukung mobilitas orang yang dapat bergerak dengan cepat dan nyaman (Damayanti, 2019) dikendarai. Kendaraankendaraan seperti ini sudah menjadi kebutuhan bagi sebagian besar orang di kota-kota besar. Apalagi bagi orang yang tuntutan kerja harus berpindahpindah tempat dengan waktu yang sempit. Mereka akan lebih nyaman untuk membawa kendaraan pribadi (Ningrum, Muchsin, \& Widodo, 2019) dari pada naik transportasi massal.

Permasalahan baru akan muncul ketika orang yang terbiasa menggunakan transportasi massal, kemudian beralih ke transportasi pribadi. Namun orang tersebut belum bisa untuk mengemudikan kendaraan pribadinya, pasti orang tersebut akan berusaha untuk bisa mengemudikan kendaraannya secara baik sesuai dengan peraturan yang berlaku (Hanafi \& Syam, 2019). Pada saat proses belajar mengemudikan kendaraan tentunya banyak hal yang harus diperhatikan. Kalau harus memakai jasa supir pribadi tentunya akan menambah biaya yang dibutuhkan. Selain pembelian bahan bakar juga harus membayar supir tersebut. Mau tidak mau bagi orang yang bersangkutan harus berusaha agar dapat mengemudikan kendaraannya sendiri. Ada beberapa cara yang dapat dilakukan agar dapat mengemudikan kendaraan. Ada yang berusaha dengan latihan sendiri tanpa bantuan orang lain (Huda, Mulyono, Rosyida, \& Wardono, 2019), tapi jelas cara ini sangat berbahaya buat pengemudi maupun kendaraan yang dikendarainya. Ada yang minta tolong diajari kepada teman atau saudaranya, namun cara ini juga tidak kalah besar resikonya karena yang mengajari tidak dapat mengendalikan kendaraan ketika dalam situasi yang berbahaya. Cara ketiga yang dirasa paling aman adalah dengan sekolah atau kursus mengemudi. Kenapa ini dikatakan paling aman, karena setiap kendaraan yang dipakai untuk latihan sudah diubah sistem pengendaliannya menjadi ganda baik itu rem maupun koplingnya, sehingga pelatih atau instruktur juga dapat melakukan pengereman ketika dalam situasi yang berbahaya (Napitupulu, Hasibuan, \& Hidayat, 2019).

Dalam penelitian ini penulis membantu mengatasinya dengan membangun sistem informasi sekolah mengemudi yang dibuat menggunakan sarana website (Kirlyana \& Rosyida, 2016) dengan 
menggunakan model Rapid Application Development (RAD). Model RAD melakukan pengecekan pemakaian kembali untuk mengurangi waktu pengujian secara keseluruhan (Ariyati, 2018). Melalui sistem ini orang dapat mengetahui segala informasi yang berkaitan dengan sekolah mengemudi. Baik itu yang berkaitan dengan jadwal latihan, nama-nama instruktur, biaya yang diperlukan, tipe mobil apa yang diinginkan ketika melaksanakan latihan serta komentar calon pengemudi yang sudah pernah mengikuti latihan di sekolah tersebut. Sistem ini sangat bermanfaat sekali bagi calon pengemudi karena dapat menyesuaikan jadwal dengan waktu yang tersedia. Bagi lembaga/sekolah mengemudi tidak harus melihat catatan sebelumnya yang dicatat di buku besar (Rosyida \& Riyanto, 2018), bisa sebagai sarana dalam mempromosikan lembaga agar bisa mendapatkan calon pengemudi sesuai dengan target yang telah ditetapkan. Serta dapat mengungguli sekolah mengemudi yang lain yang belum menggunakan sistem informasi ini.

\section{METODOLOGI PENELITIAN}

Untuk membangun sistem informasi sekolah mengemudi dengan model Rapid Application Development (RAD), karena model pengembangan perangkat lunak yang bersifat inkremental terutama untuk waktu pengerjaan yang pendek (Sukamto \& Shalahuddin, 2016). Rapid Application Development (RAD) dapat digambarkan di bawah ini yang terdiri dari 4 tahap (Lucidchart, 2018):

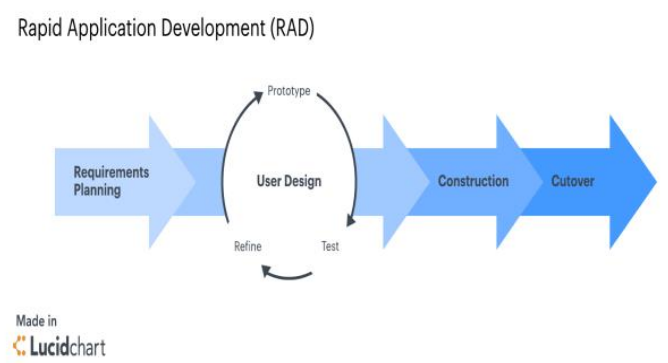

Sumber: (Lucidchart, 2018)

Gambar 1. Rapid Application Development (RAD)

Tahapan Rapid Application Development (RAD)

1. Requirements Planning

Pada tahap ini, bersama-sama menentukan tujuan dan harapan dalam membangun sistem informasi sekolah mengemudi. Yaitu dengan menganalisa masalah yang terjadi sehingga menjadi kendala dalam membangun sistem, menentukan apa yang dibutuhkan pengguna sehingga mencapai tujuan dari sistem tersebut.

\section{User Design}

Tahap selanjutnya user design yang memiliki 3 bagian, dimana bagian tersebut dilakukan bersamasama dalam proses berulang agar dapat memenuhi kebutuhan sistem (Lucidchart, 2018). Tahapan ini untuk menyelesaikan masalah fungsi dan desain antar muka agar sistem dapat berjalan dan dikembangkan dengan baik.

a. Prototype

Pada bagian ini, dilakukan sebuah prototype sistem informasi sekolah mengemudi beserta dengan fungsinya. Prototype yang dibuat dan didemonstrasikan untuk dikoreksi agar tidak terjadi kesalahpahaman dan dapat diberi masukan untuk dilakukan perubahan sehingga menjadi sistem yang sesuai dengan tujuannya.

b. Testing

Setelah itu, tahap ini dilakukan testing, untuk menguji prototype agar tidak terjadi kesalahan di setiap sistem yang dijalankan.

c. Refine

Pada tahap ini masukan-masukan yang telah diberikan, yang akan diimplementasikan pada sistem informasi sekolah mengemudi ini.

3. Rapid Construction

Pada tahap ketiga memastikan semuanya berjalan lancar dan sesuai dengan tujuan yang diharapkan. Tahap ini masih dapat memberi masukan selama proses berlangsung. Dapat menyarankan perubahan atau ide-ide baru yang dapat menyelesaikan masalah. Dimana tahap ini mengambil prototype dan sistem beta mengubahnya menjadi model kerja.

4. Cutover

Tahap akhir yaitu tahap implementasi sistem informasi sekolah mengemudi yang dapat digunakan oleh pengguna, selain itu memberikan informasi penggunaan sistem informasi sesuai dengan tujuannya.

\section{HASIL DAN PEMBAHASAN}

Penggunaan model Rapid Application Development (RAD) pada sistem informasi sekolah mengemudi memliki 4 tahapan dalam mendesain sistem yang akan dibangun, yaitu:

\section{Requirements Planning}

Menganalisa kebutuhan dalam menentukan sistem informasi yang dihasilkan sangatlah penting dalam keberhasilan sistem tersebut. Kebutuhan pengguna yang dibutuhkan berbeda-beda dalam pembuatan sistem informasi sekolah mengemudi, diantaranya:

a. Admin dan member dapat melakukan login dengan memasukkan kode admin bagi admin, email bagi member yang sudah mendaftar beserta password pada sistem informasi sekolah mengemudi.

b. Admin mengelola paket latihan mengemudi dan member dapat memilihnya.

c. Admin mengelola data mobil dan instruktur di sekolah mengemudi.

d. Admin dapat melihat data member yang mengikuti latihan mengemudi.

e. Admin dapat melihat, mengubah notifikasi testimoni dan member memberikan testimoni

f. Member dapat mencetak absensi mengikuti latihan mengemudi.

g. Admin dapat melihat dan member mencetak 
laporan transaksi.

h. Admin dan member dapat melakukan logout pada sistem informasi sekolah mengemudi.

Sedangkan analisa lainnya dalam membangun sistem informasi sekolah mengemudi untuk memproses semua kebutuhan yang diperlukan untuk mengendalikan sisem informasi tersebut, yaitu:

a. Keamanan pengguna harus terjaga dalam menggunakan sistem tersebut dengan melakukan login dengan memasukkan email dan password.

b. Sistem yang dibuat harus dapat digunakan oleh semua pengguna sesuai degan fungsinya

c. Setelah menggunakan sistem tersebut pengguna diharuskan melakukan logout agar menjaga keamanannya.

\section{User Design}

Untuk mendesign sistem sekolah mengemudi ini dibutuhkan diagram yang berkaitan antar tabel dalam suatu database sistem yaitu diagram Entity Diagram Relationship (ERD).Dalam diagram ERD terdapat kardinalitas relasi yang terjadi di antara entitas. Entitas yang dibuat dalam membangun sistem ini terdiri dari 11 entitas. Dari entitas tersebut dibuatkan struktur pengkodean untuk atribut yang merupakan primary key, fungsinya agar dapat menciri-cirikan nilai dari kode tersebut.

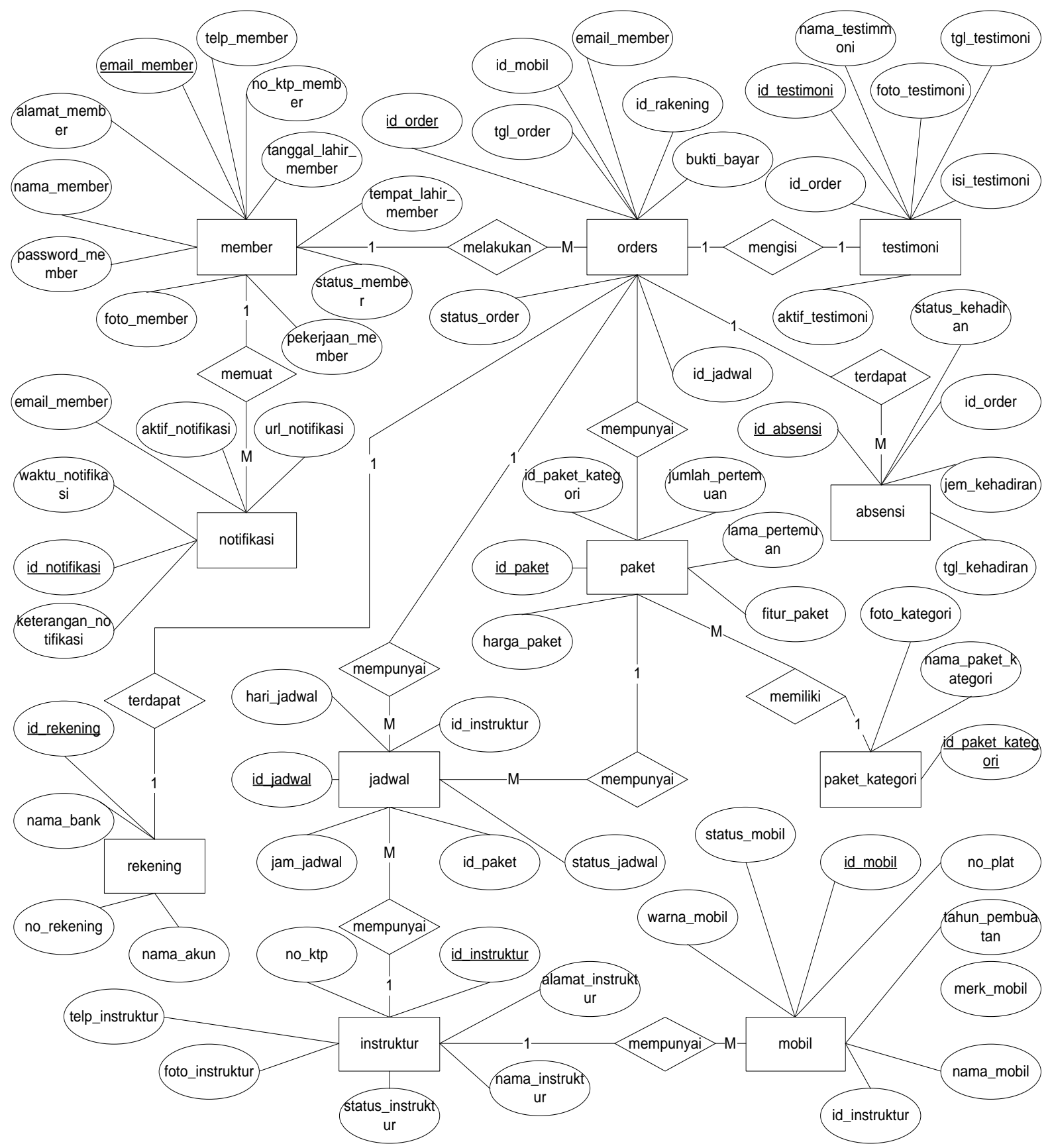

Sumber: (Penelitian, 2019)

Gambar 2. Entity Diagram Relationship (ERD) 
Dalam membangun sistem yang dapat diharapkan dapat berjalan dengan baik pemodelan secara visual dapat digambarkan dengan Unified Modelling Language (UML) yaitu diagram use case, untuk menspesifikasikan, menggambarkan, membangun dan dokumentasi dari sistem perangkat lunak.

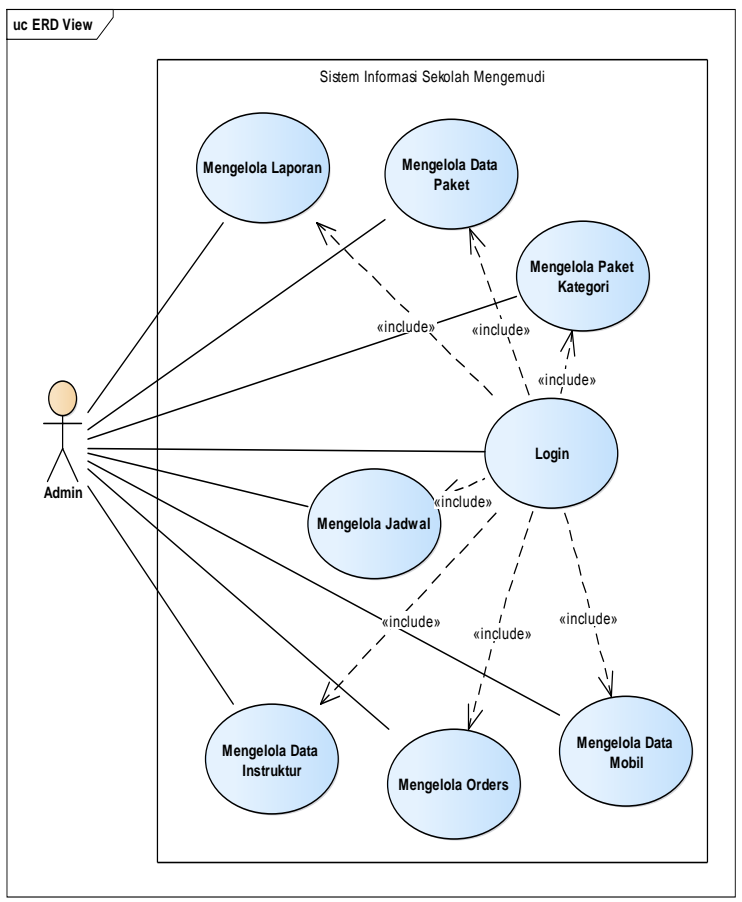

Sumber: (Penelitian, 2019)

Gambar 3. Diagram Use Case Admin

\section{Rapid Construction}

Pada tahap ini dibuatkan struktur navigasi member dan struktur navigasi admin. Dimana dengan struktur navigasi ini dibentuk penggambaran yang dapat memudahkan pengguna dalam penggunaan sistem informasi sekolah mengemudi berjalan dengan baik.

a. Struktur Navigasi Halaman Member

Struktur navigasi halaman member menggunakan tipe struktur navigasi non-linier.

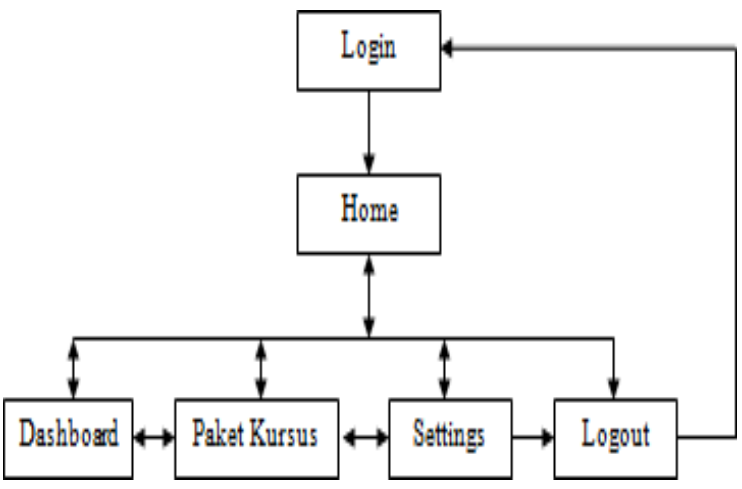

Sumber: (Penelitian, 2019)

Gambar 4. Struktur Navigasi Halaman Member

b. Struktur Navigasi Halaman Admin

Struktur navigasi halaman member menggunakan tipe struktur navigasi non-linier

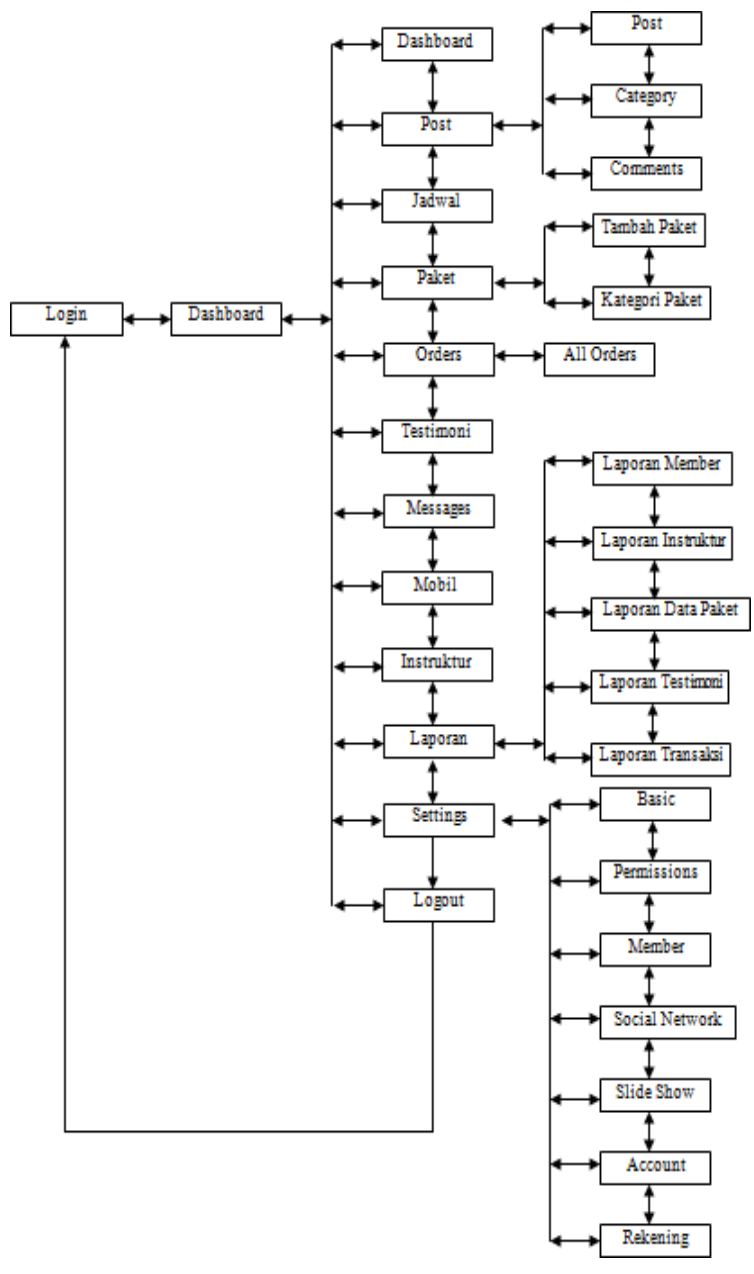

Sumber: (Penelitian, 2019)

Gambar 5. Struktur Navigasi Halaman Admin

Alasan penggunaan struktur navigasi campuran dan non-linier ini disebabkan karena sifat dari struktur navigasi ini yang sangat interaktif, dimana menghasilkan sistem yang membuat penggunanya dapat dengan leluasa menelusuri sistem ini.

\section{Cutover}

Implementasi hasil dari desain sistem informasi sekolah mengemudi merupakan sistem informasi berbasis web. Dimana sistem ini merupakan sistem yang dapat berjalan sesuai dengan dibutuhkan. Adapun implementasinya sebagai berikut:

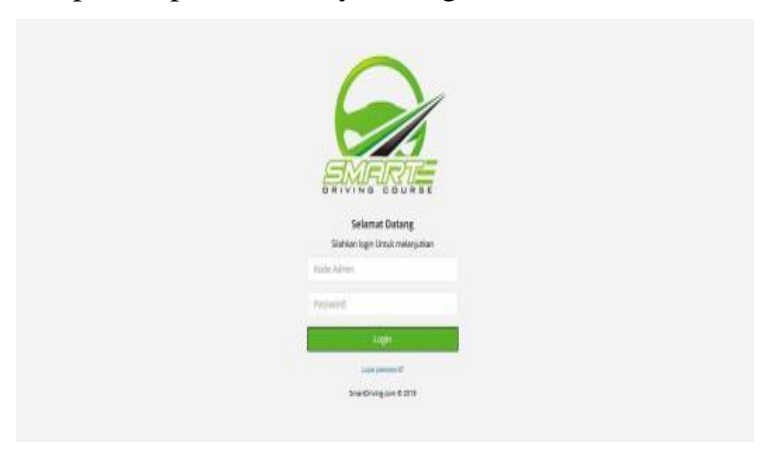

Sumber: (Penelitian, 2019)

Gambar 6. Halaman Login Untuk Admin 
Gambar 6. merupakan halaman login untuk admin agar dapat mengelola sistem informasi sekolah mengemudi dengan memasukkan kode admin dan password.

\section{Login Member}

\section{8}

\section{a}

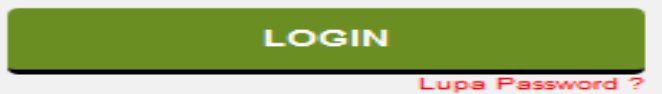

Sumber: (Penelitian, 2019)

Gambar 7.Halaman Login Untuk Member

Gambar 7 merupakan halaman login untuk member agar dapat mendaftar untuk mengikuti latihan mengemudi dengan memasukkan email dan pasword.

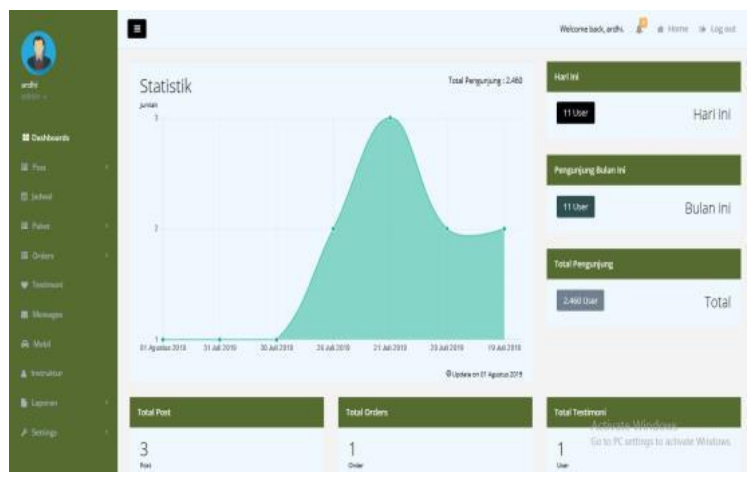

Sumber: (Penelitian, 2019)

Gambar 8.Halaman Home Admin

Gambar 8 berikut merupakan tampilan awal sistem informasi sekolah mengemudi untuk halaman admin.

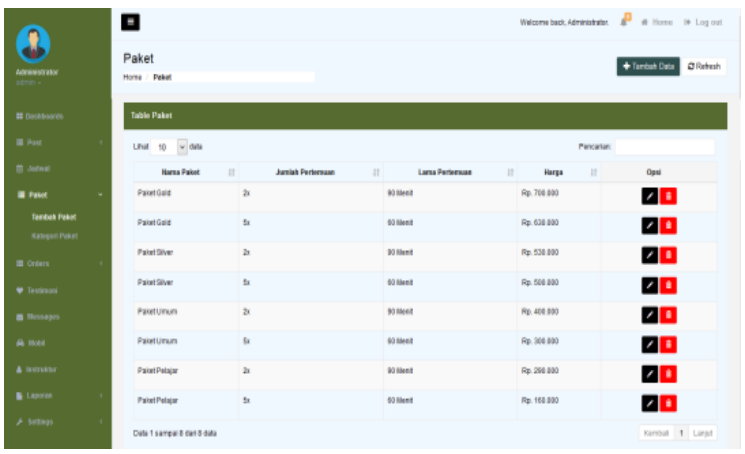

Sumber: (Penelitian, 2019)

Gambar 9. Halaman Admin Mengelola Data Paket

Gambar 9 merupakan halaman admin untuk mengelola data paket mengikuti latihan mengemudi.

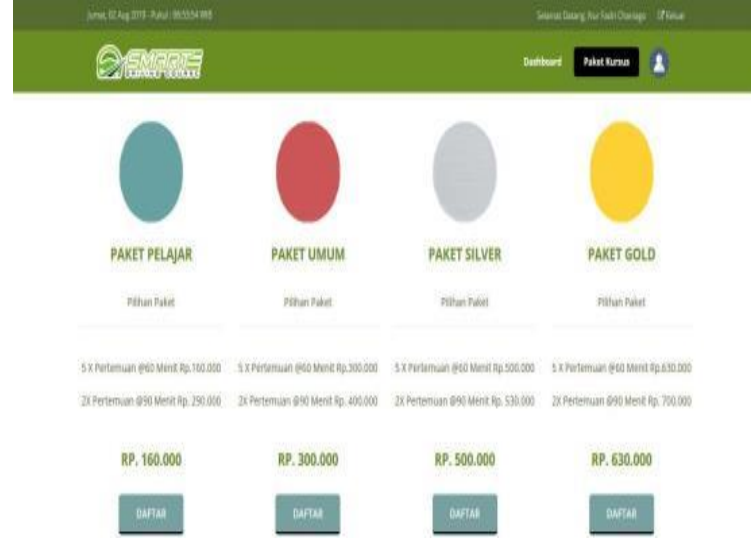

Sumber: (Penelitian, 2019)

Gambar 10. Halaman Member Memilih Paket

Gambar 10 merupakan halaman member untuk melihat dan memilih paket mengikuti latihan mengemudi.

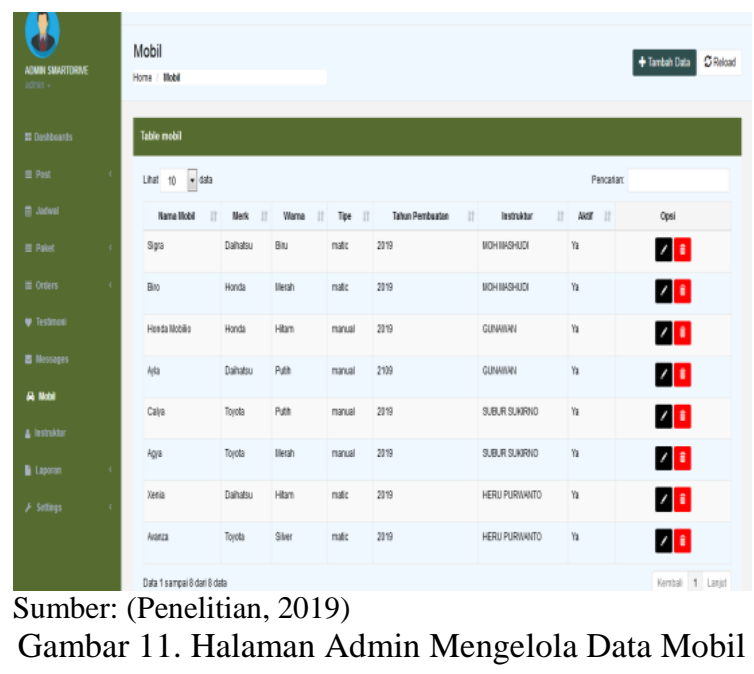

Gambar 11 merupakan halaman admin untuk mengelola data mobil yang ada pada sekolah mengemudi.

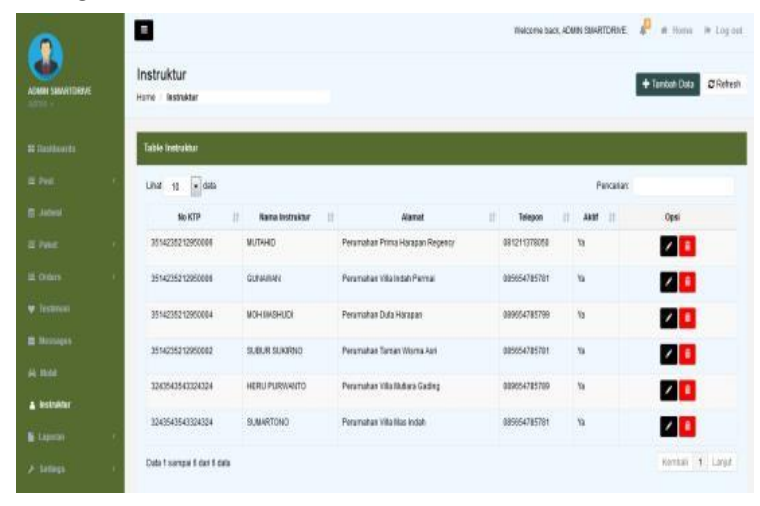

Sumber: (Penelitian, 2019)

Gambar 12. Halaman Admin Mengelola Data Instruktur

Gambar 12 merupakan halaman admin untuk mengelola data instruktur pada sekolah mengemudi. 


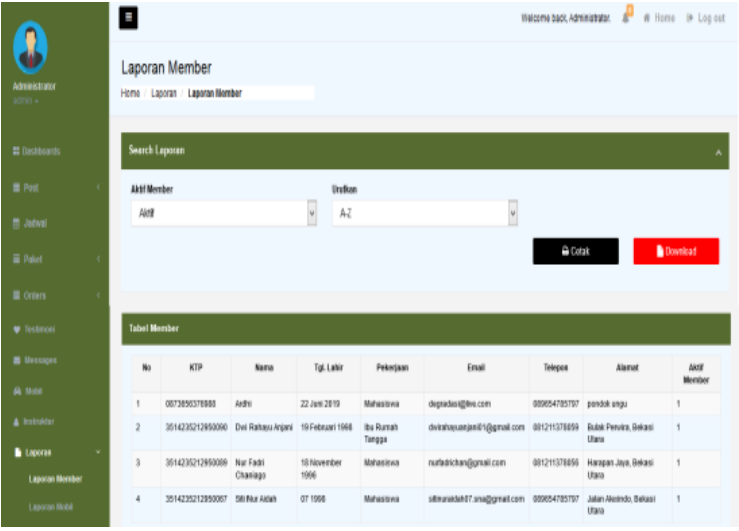

Sumber: (Penelitian, 2019)

Gambar 13. Halaman Admin Melihat Data Member

Gambar 13 merupakan halaman admin untuk melihat data member yang mengikuti sekolah mengemudi.

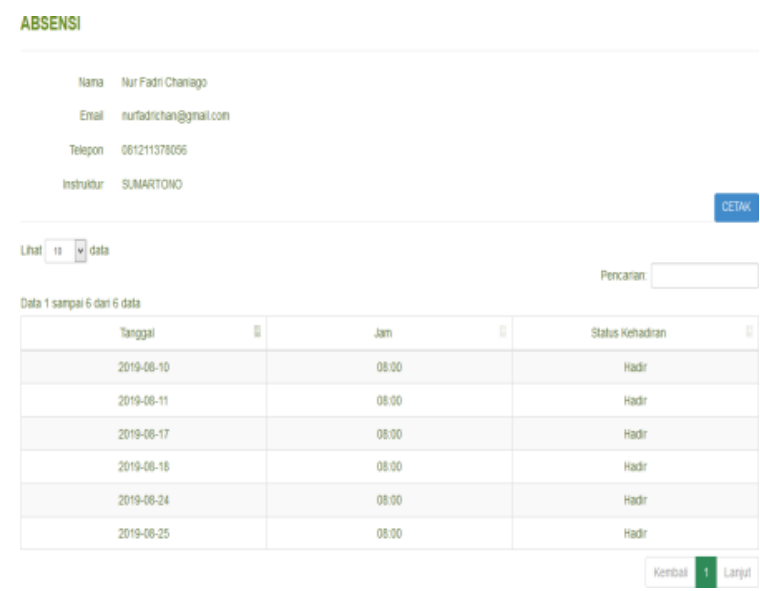

Sumber: (Penelitian, 2019)

Gambar 14. Halaman Member Mencetak Kehadiran

Gambar 14 merupakan halaman member untuk mencetak kehadiran dalam mengikuti sekolah mengemudi.

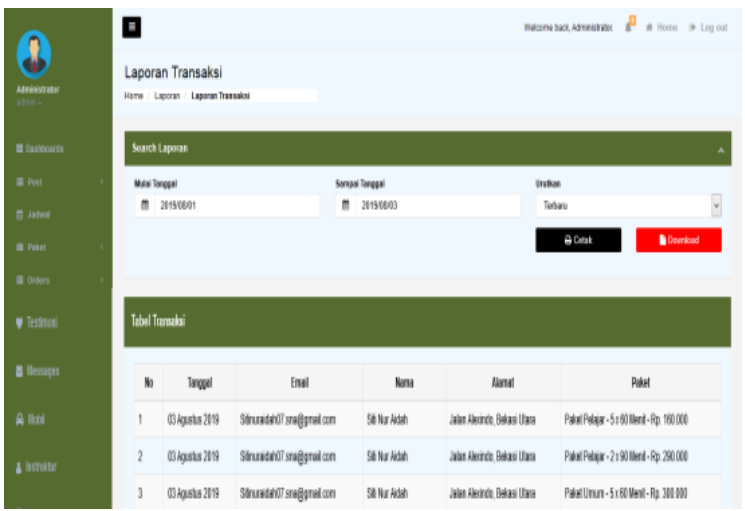

Sumber: (Penelitian, 2019)

Gambar 15. Halaman Admin Laporan Transaksi

Gambar 15 merupakan halaman admin untuk melihat dan mencetak laporan transaksi di sekolah mengemudi.
Pengujian terhadap sistem informasi sekolah mengemudi menggunakan blackbox testing yang fokus terhadap proses masukan dan keluaran program.

Tabel 1. Hasil Pengujian Black Box Testing Halaman Login Admin

\begin{tabular}{|c|c|c|c|}
\hline No & Skenario pengujian & $\begin{array}{c}\text { Hasil yang } \\
\text { Diharapkan }\end{array}$ & $\begin{array}{c}\text { Kesimpu } \\
\text { lan }\end{array}$ \\
\hline 1. & $\begin{array}{l}\text { Kode admin dan } \\
\text { password tidak diisi } \\
\text { kemudian klik } \\
\text { tombol login } \\
\text { Test case: } \\
\text { Kode admin: } \\
\text { (kosong) } \\
\text { Password: (kosong) }\end{array}$ & $\begin{array}{l}\text { Sistem akan } \\
\text { menolak akses } \\
\text { login dan } \\
\text { menampilkan } \\
\text { "Kode Admin } \\
\text { dan Password } \\
\text { Tidak Boleh } \\
\text { Kosong!" } \\
\text { Hasil } \\
\text { Pengujian: } \\
\text { Sesuai harapan }\end{array}$ & Valid \\
\hline 2. & $\begin{array}{l}\text { Mengetikkan Kode } \\
\text { admin dan } \\
\text { password tidak diisi } \\
\text { atau kosong } \\
\text { kemudian klik } \\
\text { tombol login } \\
\text { Test case: } \\
\text { Kode admin: ADM08 } \\
\text { (benar) } \\
\text { Password: (kosong) }\end{array}$ & $\begin{array}{l}\text { Sistem akan } \\
\text { menolak akses } \\
\text { login dan } \\
\text { menampilkan } \\
\text { "Password } \\
\text { Tidak Boleh } \\
\text { Kosong!" } \\
\text { Hasil } \\
\text { Pengujian: } \\
\text { Sesuai harapan }\end{array}$ & Valid \\
\hline 3. & $\begin{array}{l}\text { Kode admin tidak } \\
\text { diisi(kosong) dan } \\
\text { password diisi } \\
\text { kemudian klik } \\
\text { tombol login } \\
\text { Test case: } \\
\text { Kode admin: } \\
\text { (kosong) } \\
\text { Password: admin } \\
\text { (benar) }\end{array}$ & $\begin{array}{l}\text { Sistem akan } \\
\text { menolak akses } \\
\text { login dan } \\
\text { menampilkan } \\
\text { "Kode Admin } \\
\text { dan Password } \\
\text { Tidak Boleh } \\
\text { Kosong!" } \\
\text { Hasil } \\
\text { Pengujian: } \\
\text { Sesuai harapan }\end{array}$ & Valid \\
\hline 4. & $\begin{array}{l}\text { Mengetikkan salah } \\
\text { satu kondisi salah } \\
\text { pada Kode admin } \\
\text { atau password } \\
\text { kemudian klik } \\
\text { tombol login } \\
\text { Test case: } \\
\text { Kode admin: ADM08 } \\
\text { (benar) } \\
\text { Password: } 1234 \\
\text { (salah) }\end{array}$ & $\begin{array}{l}\text { Sistem akan } \\
\text { menolak akses } \\
\text { login dan } \\
\text { menampilkan } \\
\text { "Kode Admin } \\
\text { atau Password } \\
\text { Salah,Ulangi!" } \\
\text { Hasil } \\
\text { Pengujian: } \\
\text { Sesuai harapan }\end{array}$ & Valid \\
\hline 5. & $\begin{array}{l}\text { Mengetikkan Kode } \\
\text { admin (salah) dan } \\
\text { password dengan } \\
\text { data yang benar } \\
\text { kemudian klik } \\
\text { tombol login } \\
\text { Test case: } \\
\text { Kode admin : } \\
\text { ADM081 (salah) } \\
\text { Password: admin } \\
\text { (benar) }\end{array}$ & $\begin{array}{l}\text { Sistem akan } \\
\text { menolak akses } \\
\text { login dan } \\
\text { menampilkan } \\
\text { "Kode admin } \\
\text { atau Password } \\
\text { Salah, Ulangi" } \\
\text { Hasil } \\
\text { Pengujian: } \\
\text { Sesuai harapan }\end{array}$ & Valid \\
\hline
\end{tabular}




\begin{tabular}{|c|c|c|c|}
\hline 6. & $\begin{array}{l}\text { Mengetikkan Kode } \\
\text { admin dan password } \\
\text { dengan data yang } \\
\text { benar kemudian klik } \\
\text { tombol login } \\
\text { Test case: } \\
\text { Kode admin: ADM08 } \\
\text { (benar) } \\
\text { Password: admin } \\
\text { (benar) }\end{array}$ & $\begin{array}{l}\text { Sistem } \\
\text { menerima akses } \\
\text { login dan } \\
\text { kemudian } \\
\text { langsung } \\
\text { menampilkan } \\
\text { menu admin. } \\
\text { Hasil } \\
\text { Pengujian: } \\
\text { Sesuai harapan }\end{array}$ & Valid \\
\hline
\end{tabular}

Tabel 2. Hasil Pengujian Black Box Testing Halaman Tambah Paket Kursus

\begin{tabular}{|c|c|c|c|}
\hline $\begin{array}{l}\mathbf{N} \\
\mathbf{0}\end{array}$ & $\begin{array}{c}\text { Skenario } \\
\text { pengujian }\end{array}$ & $\begin{array}{c}\text { Hasil yang } \\
\text { diharapkan }\end{array}$ & $\begin{array}{l}\text { Kesim } \\
\text { pulan }\end{array}$ \\
\hline 1 & $\begin{array}{l}\text { Semua text box } \\
\text { (kolom data) tidak } \\
\text { diisi kemudian, klik } \\
\text { tombol Publish } \\
\text { Test case: } \\
\text { Nama: Paket Pelajar } \\
\text { (benar) } \\
\text { Jumlah pertemuan: } \\
\text { (kosong) } \\
\text { Lama pertemuan: } \\
\text { (kosong) } \\
\text { Harga paket: } \\
\text { (kosong) }\end{array}$ & $\begin{array}{l}\text { Sistem akan } \\
\text { menolak untuk } \\
\text { menyimpan dan } \\
\text { menampilkan } \\
\text { "Jumlah Tidak } \\
\text { Boleh Kosong!" } \\
\text { Hasil } \\
\text { Pengujian: } \\
\text { Sesuai harapan }\end{array}$ & Valid \\
\hline 2 & $\begin{array}{l}\text { Text box (kolom } \\
\text { data) yang diisi } \\
\text { hanya text box } \\
\text { Lama Pertemuan } \\
\text { pada form input dan } \\
\text { yang lainnya tidak } \\
\text { diisi. Kemudian klik } \\
\text { tombol Publish } \\
\text { Test case: } \\
\text { Jumlah pertemuan: } \\
2 \text { (benar) } \\
\text { Lama pertemuan: } \\
\text { (kosong) } \\
\text { Harga paket: } \\
\text { (kosong) }\end{array}$ & $\begin{array}{l}\text { Sistem akan } \\
\text { menolak untuk } \\
\text { menyimpan dan } \\
\text { menampilkan } \\
\text { "Lama Tidak } \\
\text { Boleh Kosong!" } \\
\text { Hasil } \\
\text { Pengujian: } \\
\text { Sesuai harapan }\end{array}$ & \\
\hline 3 & $\begin{array}{l}\text { Text box (kolom } \\
\text { data) yang diisi } \\
\text { hanya text box } \\
\text { Lama Pertemuan } \\
\text { pada form input dan } \\
\text { yang lainnya tidak } \\
\text { diisi. Kemudian klik } \\
\text { tombol Publish } \\
\text { Test case: } \\
\text { Jumlah pertemuan: } \\
2 \text { (benar) } \\
\text { Lama pertemuan: } \\
90 \text { menit (benar) } \\
\text { Harga paket: } \\
\text { (kosong) }\end{array}$ & $\begin{array}{l}\text { Sistem akan } \\
\text { menolak untuk } \\
\text { menyimpan dan } \\
\text { menampilkan } \\
\text { "Harga Paket } \\
\text { Tidak Boleh } \\
\text { Kosong!" } \\
\text { Hasil } \\
\text { Pengujian: } \\
\text { Sesuai harapan }\end{array}$ & Valid \\
\hline 4 & $\begin{array}{l}\text { Mengisi semua text } \\
\text { box dengan lengkap } \\
\text { kemudianklik }\end{array}$ & $\begin{array}{l}\text { Sistem akan } \\
\text { menerima akses } \\
\text { user dan } \\
\end{array}$ & Valid \\
\hline
\end{tabular}

\begin{tabular}{ll}
\hline tombol Publish & menyimpan data \\
Test case $:$ & ke database \\
Jumlah pertemuan: & Hasil \\
2 (benar) & Pengujian: \\
Lama pertemuan: & Sesuai harapan \\
90 menit (benar) & \\
Harga paket: & \\
160000 (benar) & \\
\hline
\end{tabular}

\section{KESIMPULAN}

Proses belajar mengemudikan kendaraan dengan baik dan benar tentunya banyak hal yang harus diperhatikan agar memiliki Surat Ijin Mengemudi (SIM). Oleh karena itu, pada penelitian ini sistem informasi sekolah mengemudi berbasis web dibangun menggunakan model Rapid Application Development (RAD), karena dengan waktu yang singkat dapat membangun sistem dalam 4 tahapan. Sistem informasi sekolah mengemudi menampilkan segala informasi yang berkaitan dengan pembelajaran mengemudi yang diterapkan. Dengan sistem ini, calon pengemudi dapat mengetahui tentang jadwal latihan, nama-nama instruktur, biaya yang diperlukan, tipe mobil apa yang diinginkan ketika melaksanakan latihan serta komentar calon pengemudi yang sudah pernah mengikuti latihan di sekolah tersebut. Selain itu, bagi sekolah mengemudi dapat mempromosikan agar dapat menarik calon pengemudi lainnya.

\section{REFERENSI}

Ariyati, I. (2018). Pengembangan Sistem Informasi Perpustakaan Sekolah Dengan Rapid Application Development. Jurnal Pilar Nusa Mandiri, 14(1), 55-60. https://doi.org/10.33480/PILAR.V14I1.90

Damayanti, V. D. (2019). Analisis "GAP" Keinginan Pelanggan Versus Keinginan Owner Café Terhadap Variabel Fasilitas Pada Café Kalpa Tree. E-Proceeding of Management, 6(2), 2228-2236. https://doi.org/.1037//0033-2909.I26.1.78

Hanafi, M. A. N., \& Syam, S. (2019). Analisis Kinerja Keuangan Berdasarkan Prinsip Camel Pada Pt.Bank Rakyat Indonesia (BRI) Yang Terdaftar Di Bursa Efek Indonesia. PAY Jurnal Keuangan Dan Perbankan, 1(1), 4857. Retrieved from http://ejournals.umma.ac.id/index.php/pay/arti cle/view/216

Huda, M. N., Mulyono, M., Rosyida, I., \& Wardono, W. (2019). Kemandirian Belajar Berbantuan Mobile Learning. PRISMA, Prosiding Seminar Nasional Matematika, 2, 798-806. Retrieved from

https://journal.unnes.ac.id/sju/index.php/prism a/article/view/29270 
Jaya, F. S., \& Hasddin, H. (2019). Kajian Kesehatan Lingkungan Perkotaan Menurut Aspek Daya Dukung Kawasan Jalur Hijau Jalan Dalam Pengendalian Cemaran Gas Buang Kendaraan Bermotor Di Kota Raha. Jurnal Akrab Juara, 4(4), 159-177. Retrieved from http://akrabjuara.com/index.php/akrabjuara/art icle/view/810

Kirlyana, B., \& Rosyida, S. (2016). Sistem Informasi Penjualan Sepatu Handmade Berbasis Web. Information Management for Educators and Professionals, 1(1), 22-31. Retrieved from http://www.ejournalbinainsani.ac.id/index.php/IMBI/article/view/1 53

Lesmono, I. D. (2019). Animasi Berbasis Multimedia Untuk Siswa Berupa Pengenalan Moda Transportasi Dengan Metode Waterfall. Swabumi, $7(1)$, $20-30$. https://doi.org/10.31294/swabumi.v7i1.5572

Lucidchart. (2018). 4 Phases of Rapid Application Development Methodology. Retrieved December 17, 2019, from https://www.lucidchart.com/blog/rapidapplication-development-methodology

Napitupulu, M. A., Hasibuan, E. J., \& Hidayat, T. W. (2019). Persepsi Tenaga Kerja Indonesia Terhadap Gaya Komunikasi Instruktur dalam Memberikan Pembekalan Materi. PERSPEKTIF, 6(1), 13-17. https://doi.org/10.31289/PERSPEKTIF.V6I1.2 506

Ningrum, S. W., Muchsin, S., \& Widodo, R. (2019). Evaluasi Kinerja Pelayanan Dinas Perhubungan Dalam Bidang Transportasi Umum Perkotaan (Studi Pada Dinas
Perhubungan Kota Malang Provinsi Jawa Timur). Respon Publik, 13(2), 53-61. Retrieved from http://riset.unisma.ac.id/index.php/rpp/article/v iew/2118

Penelitian, D. H. (2019). Analisa Model RAD Dalam Membangun Sistem Informasi Sekolah Mengemudi.

Riyanto, V., Rosyida, S., \& Ridwansyah. (2018). Evaluasi Faktor Keberhasilan Sistem Informasi Transportasi Online Berbasis Mobile Dalam Perspektif Kepuasan Pelanggan. Laporan Penelitian Dosen Pemula. Rosyida, S., \& Riyanto, V. (2018). Sistem Informasi Pengelolaan Data Laundry Pada Rumah Laundry Bekasi. In Laporan Akhir Penelitian. Bekasi.

Sukamto, R. A., \& Shalahuddin, M. (2016). Rekayasa Perangkat Lunak. Bandung: Informatika Bandung.

\section{PROFIL PENULIS}

Vivi Rahmawati, A.Md. Kom. Tahun 2019 lulus dari Program Diploma Tiga (D3) Program Studi Sistem Informasi Universitas Bina Sarana Informatika.

Susy Rosyida, M.Kom. Tahun 2010 lulus dari Program Strata Satu (S1) Program Studi Sistem Informasi STMIK Nusa Mandiri Jakarta. Tahun 2013 lulus dari Program Strata Dua (S2) Program Studi Magister Ilmu Komputer STMIK Nusa Mandiri Jakarta. Saat ini bekerja sebagai tenaga pengajar di STMIK Nusa Mandiri Jakarta. 